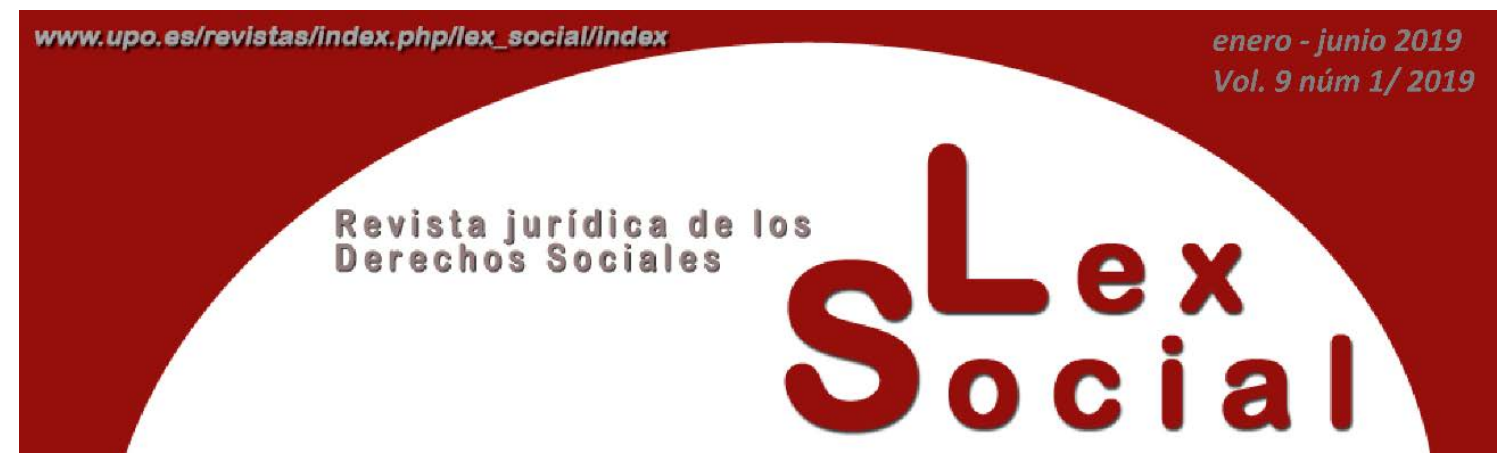

\title{
MATRIMONIO Y ORIENTACIÓN SEXUAL: LA FUERZA EXPANSIVA DEL DERECHO A LA NO DISCRIMINACIÓN \\ Comentario de las sentencias Taddeucci y Coman
}

\section{MARRIAGE AND SEXUAL ORIENTATION: THE EXPANSIVE STRENGTH OF THE RIGHT TO NONDISCRIMINATION Commentary on Taddeucci and Coman judgments}

\author{
ALICIA RIVAS VAÑÓ
}

Profesora asociada de Derecho Constitucional Universidad Pablo de Olavide

Artículo recibido el 15 de marzo de 2019

Artículo aceptado el 21 de marzo de 2019

\section{RESUMEN}

La evolución de la protección de la diversidad sexual en las instituciones europeas es incontestable, aun cuando aún es necesario ampliarla a derechos tradicionalmente vetados a las minorías LGBTI. En este sentido, las últimas respuestas jurisprudenciales del TEDH y del TJUE apuntan en direcciones distintas respecto de un asunto tan controvertido como el reconocimiento de las parejas del mismo sexo, y en última instancia, del matrimonio homosexual. En este artículo se acomete el análisis de los últimos casos que han dado lugar a esta diferente interpretación.

PAlAbRAs ClAve: LGTBI, diversidad sexual, igualdad, no discriminación, parejas del mismo sexo, matrimonio, familia, jurisprudencia europea, Taddeucci, Coman. 


\begin{abstract}
The evolution of the protection of sexual diversity by the European institutions is indisputable, even if it is still necessary to grant it in relation to rights traditionally not recognized to LGBTI minorities. In this sense, the last jurisprudence of the ECHR and the CJEU give different answers when dealing with such a controversial issue as it is the recognition of same-sex partners, and ultimately, same-sex marriage. This paper tries to analyze the most recent cases leading to such a different interpretation.
\end{abstract}

KEY WoRDs: LGBTI, sexual diversity, equality, nondiscrimination, same-sex partners, marriage, family, European jurisprudence, Taddeucci, Coman.

\title{
SUMARIO
}

\section{Introducción.}

2. La regulación jurídica de las parejas del mismo sexo en los Estados miembros de la UE y del Consejo de Europa.

3. La respuesta del TEDH: Taddeucci.

4. La respuesta del TJUE: Coman.

5. Conclusiones.

6. Bibliografía.

\section{Introducción.}

El concepto $L G B T I^{1}$ primero o si se quiere, más recientemente, diversidad sexual, relativamente nuevo en nuestro entorno jurídico, hace referencia a toda una serie de manifestaciones humanas relacionadas con la orientación sexual y la identidad sexual y de género que exigen, en buena medida, de una atención especializada por parte del Derecho, y que tienen en común una buena parte de sus reivindicaciones, aun cuando hablamos en muchos casos de situaciones muy dispares ${ }^{2}$.

\footnotetext{
${ }^{1}$ Siglas que hacen referencia a Lesbian, Gay, Bisexual, Transsexual e Intersexual.

${ }^{2}$ Pensemos por ejemplo en las necesidades particulares del colectivo trans, en relación con la identidad de género, y cómo sus reivindicaciones se han diluido parcialmente entre las del colectivo homosexual y la protección frente a discriminación por género, quedando de este modo parte de sus exigencias ocultadas.
} 
A lo largo del tiempo, particularmente desde los años setenta del siglo pasado hasta ahora, estos colectivos se han ido agrupando y organizando paulatinamente hasta adquirir un músculo de activismo social y jurídico difícilmente comparable, a través de organizaciones bien articuladas en torno a fines comunes. Un claro ejemplo de ello es ILGA (International Lesbian and Gay Association) y en particular, en lo que aquí nos atañe, su vertiente regional europea ${ }^{3}$, que agrupa y coordina a organizaciones nacionales de toda Europa, y que ha logrado, a lo largo del tiempo, junto con otras importantes organizaciones y activistas ${ }^{4}$, modificar tanto los textos legislativos de la Unión Europea (en adelante UE) para incluir parte de sus reivindicaciones, como la respuesta jurisprudencial de los Altos tribunales, tanto por parte del Tribunal de Justicia de la UE (en adelante TJUE) como del Tribunal Europeo de Derechos Humanos (TEDH). En este último ámbito es donde se ha logrado romper en cierta medida la reticencia de los legisladores europeos a la protección del colectivo LGBTI, a través de la litigación estratégica $^{5}$ puesta en marcha por organizaciones concretas en muchos casos, pero también por personas particulares, que ha demostrado una gran eficacia en la paulatina transformación de la respuesta del Derecho a las necesidades vinculadas con la diversidad sexual ${ }^{6}$.

Es en este contexto en el que vamos a analizar la incidencia de las aportaciones jurisprudenciales europeas en la transformación del concepto de familia, primero, y en la crisis del concepto tradicional de matrimonio, después, como consecuencia del empuje LGBTI, a través de la aplicación de la prohibición de discriminación por orientación sexual, como seguidamente veremos.

\footnotetext{
${ }^{3}$ Su página web es una importante fuente de información jurídica y sociológica: www.ilga-europe.org

${ }^{4}$ Hablamos de organizaciones como AIRE Centre, ECSOL (European Commission on Sexual Orientation Law), Liberty, Stonewall, a modo de ejemplo.

${ }^{5}$ Es mucha la investigación que sobre este fenómeno se está llevando a cabo en los últimos años, así, por ejemplo: HODSON, L. NGOs and the Struggle for Human Rights in Europe, Oxford: Hart Publishing, 2011, en la que, además, explora la naturaleza de los derechos humanos como resultado de la lucha reivindicativa de grupos de presión sociales, haciendo especial referencia a la teoría crítica del Derecho. También, SMITH, R.A. y HAIDER-MARKEL, D.P. Gay and Lesbian Americans and Political Participation: a Reference Handbook, Santa Barbara: ABC-CLIO, 2002, para un estudio de la influencia de la orientación sexual en el sistema político norteamericano; ADAM, B.D, DUYVENDAK, J.W. y KROUWEL, A. (eds.) The Global Emergence of Gay and Lesbian Politics: National Imprints of a Worldwide Movement, Philadelphia: Temple University Press, 1999, en el que se describe con detalle la historia del movimiento LGBTI en distintos países de todo el mundo, pero no desde una óptica exclusivamente europea; ADAM, B.D. The Rise of a Gay and Lesbian Movement, New York: Twayne Publishers, 1995; RAJAGOPAL, B. International Law from Below: Development, Social Movements and Third World Resistance, Cambridge: Cambridge University Press, 2003, en el que hace un interesantísimo análisis del Derecho internacional, desde la perspectiva del desafío que supone para el sistema el recurso al discurso de derechos humanos protagonizado por los movimientos sociales, y que bien puede aplicarse aunque no se menciona en esta obra, a las reivindicaciones LGBTI, algo que se hace expresamente en LOUX, A.C. "Losing the Battle, Winning the War: Litigation Strategy and Pressure Group Organisation in the Era of Incorporation”, King's Law Journal, vol. 11, n 1, 2000, pp. 90-104.

${ }^{6}$ Para un análisis pormenorizado de la evolución de la protección de la diversidad sexual en las instituciones europeas, ver RIVAS VAÑÓ, A. LGBTI en Europa: la construcción jurídica de la diversidad, Valencia: Tirant lo Blanch, 2019.
} 


\section{La regulación jurídica de las parejas del mismo sexo en los Estados miembros de la UE y del Consejo de Europa.}

Resulta necesario, antes de entrar en el análisis de la jurisprudencia de los Altos Tribunales europeos, conocer cuál es la situación de reconocimiento de las parejas del mismo sexo en los Estados que conforman el Consejo de Europa, y en los que, más reducidamente, son miembros de la $\mathrm{UE}^{7}$.

En la actualidad, son 26 los Estados del Consejo de Europa que reconocen, o bien directamente el matrimonio entre personas del mismo sexo: 14 (más en el Reino Unido, Inglaterra, Escocia y Gales); o bien a una unión de pareja de hecho con los mismos derechos que los que se reconocen a las parejas matrimoniales: 18 (entre los que se encuentran 7 Estados que tienen un doble reconocimiento, tanto del matrimonio, como de la pareja de hecho equiparable). Esto supone un 55\% del total de 47 Estados que conforman el Consejo de Europa.

Por su parte, en relación a la UE, la cifra se sitúa en 21 Estados, de un total de 28, siendo 12 (más de nuevo, en el Reino Unido, Inglaterra, Escocia y Gales), los que reconocen el matrimonio entre personas del mismo sexo, y 15 los que hacen este reconocimiento a través de la pareja de hecho con derechos iguales a los matrimoniales (en este caso, son de nuevo 7 los Estados con doble reconocimiento). El porcentaje del total, asciende por tanto al $71 \%$.

Interesante resulta aportar el dato del número de Estados que permiten el matrimonio de personas trans con personas de otro género, (lo que supone de hecho una ruptura de la idea de matrimonio en relación al sexo biológico), resultando así que 41 Estados del Consejo de Europa lo reconocen, quedando por tanto solo 6 fuera de este reconocimiento, no siendo ninguno de ellos miembro de la UE (se trata de Albania, Andorra, Liechtenstein, República de Macedonia del Norte, Mónaco y San Marino).

En los Estados en los que la equiparación con las parejas heterosexuales no es plena (aun cuando se le denomine de distinta forma, no usando el término matrimonio), observamos distintos grados de reconocimiento de la pareja homosexual, y en 20 de los Estados del Consejo de Europa no se produce ningún tipo de reconocimiento de esta realidad (excluimos aquí la situación de las personas trans), encontrándose entre éstos, los casos de 6 Estados, Bulgaria, Eslovaquia, Letonia, Lituania, Polonia y Rumanía, que

\footnotetext{
${ }^{7}$ Para conocer la situación de las personas LGBTI en Europa, resulta un instrumento de particular ayuda la memoria anual que realiza ILGA-Europe, incluyendo información actualizada, país por país, organizada por temas: Annual Review of the Human Rights Situation of Lesbian, Gay, Bisexual, Trans and Intersex People, Brussels: ILGA-Europe, 2019; así como la información recopilada en la página Rainbow Europe, https://rainbow-europe.org, de manera muy visual. Por otro lado, se ha consultado también WAALDIJK, K. Extending rights, responsibilities and status to same-sex families: trends across Europe, Consejo de Europa y Ministerio de Asuntos Exteriores de Dinamarca, marzo 2018.
} 
perteneciendo a la UE, no realizan ningún tipo de reconocimiento legal de las parejas homosexuales.

Por tanto, aunque el reconocimiento de los derechos de las parejas homosexuales parece avanzar bastante en buena parte de los Estados europeos, es cierto también que nos encontramos ante avances parciales, desiguales en los Estados en los que se están produciendo, con una enorme variedad de grados de reconocimiento y, en algunos casos, con un rechazo frontal y activo a cualquier innovación legal en este sentido, prohibiendo en los textos constitucionales y legales la posibilidad del matrimonio homosexual. En este contexto, resulta especialmente relevante la labor de los Tribunales internacionales europeos, que se encuentran en situación de establecer el estándar mínimo de reconocimiento exigible desde la perspectiva de los derechos humanos (TEDH), y tienen la capacidad de armonizar la respuesta jurídica al menos en determinados ámbitos (TJUE).

\section{La respuesta del TEDH: Taddeucci.}

La tarea llevada a cabo por el TEDH en relación a la orientación sexual supone un clarificador ejemplo respecto de varias cuestiones. Por un lado, pone de manifiesto una forma de afrontar las transformaciones en la interpretación del Derecho a través del anuncio de que éstas van a producirse, facilitando así que los Estados miembros vayan asumiendo los cambios que se avecinan de manera menos traumática que si de una modificación radical y rápida se tratara ${ }^{8}$. Por otro lado, implica la constatación de la aplicación de un concepto de no discriminación que ha sido pulido y transformado en el tiempo, debido en buena medida a las nuevas exigencias de colectivos con una creciente actividad reivindicadora, como es el compuesto por personas con orientaciones e identidades sexuales diversas.

Así, la evolución de la jurisprudencia del TEDH en materia de protección de la orientación sexual se va a articular en torno a dos elementos fundamentalmente: el derecho a la vida privada y familiar ${ }^{9}$, y el reconocimiento de la orientación sexual como motivo de protección antidiscriminatoria ${ }^{10}$ en el Convenio Europeo de Derechos

\footnotetext{
${ }^{8}$ Un interesante estudio acerca de la influencia de las decisiones del TEDH sobre derechos relacionados con la diversidad sexual en los Estados miembros puede verse en HELFER, L. y VOETEN, E. "International Courts as Agents of Legal Change: Evidence from LGBT Rights in Europe”. International Organization, vol. 68, nº 1, 2014, pg. 77-110. doi:10.1017/S0020818313000398

${ }^{9}$ Para una visión crítica de la jurisprudencia desarrollada por el TEDH en relación a la orientación sexual y la vida privada y familiar, ver HELFER, L.R. "Consensus, Coherence and the European Convention on Human Rights”. Cornell International Law Journal, vol. 26, 1993, pg. 133 ss. En relación a los límites que la protección del derecho a la vida privada ofrece al colectivo, SELVANERA, G. "Gays in Private: the Problems with the Privacy Analysis in Furthering Human Rights” Adelaide Law Review, vol. 16, 1994, pg. 331 ss.

${ }^{10}$ Sobre el concepto de discriminación en general, ver BAMFORTH, N., MALIK, M. y O’CINNEIDE, C. Discrimination Law: Theory and Context, Text and Materials, Londres: Sweet and Maxwell, 2008.
} 
Humanos (en adelante CEDH). Tanto en un caso como en el otro, la interesante evolución del contenido de estos derechos implicará transformaciones esenciales no solo en el tratamiento jurídico del colectivo LGBTI, sino también en la misma concepción esencial de estos derechos, en la relación existente entre los mismos, y en el establecimiento de una interpretación más conectiva de unos derechos con otros. Los derechos del CEDH dejarán de ser islas separadas con contenidos distintos claramente definidos, para empezar a entenderse como piezas del rompecabezas de la dignidad humana ${ }^{11}$ que hay que encajar en cada situación para lograr la adecuada protección de la persona.

Es imposible en un trabajo de estas dimensiones hacer mención siquiera de la amplísima jurisprudencia en materia de protección de la diversidad sexual desarrollada por el $\mathrm{TEDH}^{12}$, por lo que vamos tan solo a identificar, de manera muy somera, los asuntos a través de los cuales se produce un salto transformador de una jurisprudencia que ya venía anunciando los cambios impulsada por esta acción litigadora de los colectivos LGBTI. En concreto, respecto del reconocimiento de la aplicación del art. 8 del CEDH, relativo a la vida privada y familiar, es necesario mencionar el asunto Dudgeon v. Reino Unido ${ }^{13}$, que supone la culminación de sucesivas llamadas a la protección internacional del CEDH que se venían sucediendo sin éxito hasta la fecha. En un momento histórico en el que muchos Estados miembros mantenían la persecución penal de la relación sexual entre adultos del mismo sexo que consienten (particularmente incisiva en el caso de las relaciones sexuales entre hombres), el TEDH reconoce en Dudgeon que este tipo de actividad, realizada en privado, se encuentra protegida por el derecho a la vida privada, de modo que la injerencia en este ámbito a través del derecho penal supone una violación del CEDH. A partir de esta sentencia, se sucederán continuas ampliaciones del concepto de vida privada y familiar del art. 8 del CEDH para incluir paulatinamente diferentes reivindicaciones en relación a los problemas con los que se enfrentan las personas LGBTI, desde la protección otorgada a las personas transexuales ${ }^{14}$ a la presencia de homosexuales en las Fuerzas Armadas ${ }^{15}$, por poner solo dos ejemplos.

Supone esta sentencia, en su momento, un importantísimo avance en defensa del colectivo LGBTI, que sin embargo no va a resultar suficiente. La posterior jurisprudencia

\footnotetext{
${ }^{11}$ BERTOLINO, R. "La cultura moderna de los derechos y la dignidad del hombre”, Derechos y Libertades, nº7, 1999, pg. 131 ss.

${ }^{12}$ Una compilación completa de las sentencias, tanto del TEDH como del Tribunal de Justicia de la Unión Europea, se puede encontrar en WINTEMUTE, R. "Sexual orientation and gender identity discrimination: the case law of the European Court of Human Rights and the Court of Justice of the European Union”, https://www.ilga-europe.org/sites/default/files/Attachments/case_law_document_rw_2017-08-01.pdf (consultado el 12 de marzo de 2019). Para un listado completo de los diferentes asuntos que han llegado al entramado jurisdiccional del Consejo de Europa (incluyendo así a la CoEDH) hasta el 2013, se puede consultar el detallado gráfico que aporta JOHNSON, P. Homosexuality and the European Court of Human Rights, Oxon: Routledge, 2013, Appendix 2.

13 Sentencia Dudgeon v. Reino Unido, de 22 de octubre de 1981.

${ }^{14}$ Que tiene su primer exponente en la sentencia B v. Francia, de 25 de marzo de 1992.

15 Sentencia Smith y Grady v. Reino Unido y sentencia Lustig-Prean y Beckett v. Reino Unido, ambas de 27 de septiembre de 1999.
} 
del TEDH, garantizando y extendiendo el contenido del derecho a la vida privada a otras situaciones relacionadas con la diversidad sexual (tanto en su faceta de orientación sexual como en relación a la identidad sexual o de género), negará una y otra vez la conveniencia de incluir un examen en términos de discriminación por orientación sexual, única vía real para conseguir la protección del colectivo en su faceta más social. Y es que el reconocimiento de la orientación sexual como motivo de discriminación, esto es, la entrada del análisis antidiscriminatorio, la inclusión de la igualdad en el reconocimiento de los derechos del CEDH, supone una enorme ampliación, casi imposible de frenar, de los ámbitos de protección otorgados, que difícilmente van a quedar reducidos a la vida privada.

Efectivamente, en el asunto Da Silva Mouta v. Portugal ${ }^{16}$ se reconoce por primera vez que la orientación sexual es uno de los motivos protegidos por el art. 14 del CEDH (la cláusula antidiscriminatoria). Se trata éste de un artículo sin aplicabilidad autónoma, esto es, que solo puede ser activado en conexión con otros artículos del CEDH ${ }^{17}$. Y esto es así por las particulares características del concepto de igualdad en su vertiente de no discriminación, puesto que se trata de un principio cuya puesta en práctica de manera autónoma afecta necesariamente a todos los ámbitos de la vida social. Solo cabe reducir su campo de actuación convirtiéndolo en un derecho instrumental en la constitución de otros derechos con un contenido mucho más delimitado. Esto es precisamente lo que hace el CEDH, como mecanismo para circunscribirse a sí mismo a la protección de los otros derechos sustantivos que reconoce, y no tener, a través de un general reconocimiento del derecho a la no discriminación, un alcance casi universal ${ }^{18}$. Sin embargo, el TEDH ha utilizado en multitud de ocasiones este carácter no autónomo del art. 14 para negarse a examinar una controversia a la luz de su posible contenido discriminatorio, hasta tal punto que ha sido incluso objeto de duras críticas al respecto, tanto de la doctrina como de

\footnotetext{
16 Sentencia Da Silva Mouta v. Portugal, de 21 de diciembre de 1999.

${ }^{17}$ Una importante crítica a la interpretación tremendamente restrictiva del TEDH respecto de este carácter no autónomo, puede verse en la misma posición del Juez Matscher en su voto particular de la sentencia Dudgeon, cuando afirma que el TEDH "ne peut pas se soustraire à cette obligation (la de analizar la posible vulneración del art. 14) en employant des formules qui risquent de limiter excessivement la portée de l'article 14 jusqu'à le priver de toute valeur pratique (...) [L]orsque la Cour est appelée à statuer sur la violation d'une disposition de la Convention, alléguée par le requérant et contestée par le gouvernement en cause (et à la condition que la demande soit recevable), il lui incombe de se prononcer sur cela, en donnant une réponse sur le fond du problème qui a été soulevé” Sentencia Dudgeon, op. cit., voto particular del Juez Matscher, p. 36.

${ }^{18}$ El Protocolo adicional $n^{\circ} 12$, de uno de abril de 2005, incorpora al conjunto normativo del CEDH una cláusula general de no discriminación, que supera las limitaciones que el artículo 14 impone. Este protocolo adicional exige para su entrada en vigor la ratificación de al menos diez Estados. En la actualidad son 20 los que han procedido a su ratificación y/o adhesión. Para acceder al listado completo de Estados firmantes, ver https:/www.coe.int/en/web/conventions/full-list//conventions/treaty/177/signatures?p_auth=YDn2MKog (consultado el 12 de marzo de 2019). Para un análisis de este Protocolo en relación a la orientación sexual, ver HENDERSON, L. M., A New Protocol for Equality: A New Vehicle Toward Gay Rights as Human Rights? Mayo, 2010. Accesible en SSRN: https://ssrn.com/abstract=1638385 or http://dx.doi.org/10.2139/ssrn.1638385.
} 
algunos de sus magistrados, que consideran que esta postura vacía de contenido la cláusula antidiscriminatoria ${ }^{19}$.

La negativa a enfocar los asuntos relacionados con la orientación sexual desde una perspectiva de discriminación tiene su primera grieta, como decíamos, en Da Silva Mouta, un asunto en el que se trataba de una cuestión especialmente sensible como eran los derechos como progenitor del padre biológico de una menor, que había iniciado una relación homosexual, dadas las dificultades que se plantearán aún durante mucho tiempo en cuanto a la relación entre las parejas homosexuales y el cuidado de menores. Resulta también especialmente llamativo que la inclusión de la orientación sexual como motivo de protección antidiscriminatoria se hará sin prácticamente aportar argumentación al respecto, como si de una obviedad se tratara, siendo sin embargo una afirmación reiteradamente demandada por la actividad litigadora del colectivo LGBTI desde hacía muchísimo.

A partir de esta sentencia, se sucederán los asuntos en los que, renunciando a los límites auto impuestos, el TEDH empezará a desplegar toda la capacidad protectora del art. 14, en diversos ámbitos tales como los asuntos relacionados con la posibilidad de adopción por parejas homosexuales ${ }^{20}$, subrogación en contrato de alquiler ${ }^{21}$, cobertura sanitaria $^{22}$, consideración como familia a efectos de concreción de pensión de alimentos ${ }^{23}$. Y hará esto desde una perspectiva más integradora de la relación entre el principio de igualdad y el resto de derechos sustantivos del CEDH, reafirmando la necesidad de protección de la faceta comunitaria del derecho de libertad personal que supone la protección de la vida privada y familiar de la comunidad LGBTI. En efecto, sin la especial defensa de la protección antidiscriminatoria, la proyección social (como no puede ser de otra manera, al tratarse de una característica personal que supone la posibilidad de interacción con otras personas del mismo sexo, o la posibilidad de ser identificados por otras personas como pertenecientes a un sexo biológico determinado), de la diversidad sexual no podría desplegarse, relegando al colectivo al estricto ámbito de la intimidad personal en sus relaciones sentimentales y familiares, y coartando la manifestación hacia la colectividad de sus identidades.

${ }^{19}$ Es muy amplia la bibliografía al respecto. Por todos, SURREL, H. (Dir.) Le Droit à la NonDiscrimination au Sens de la Convention Européenne des Droits de l'Homme, Actes du colloque des 9 et 10 novembre 2007 organisé par l'Institut de Droit Européen des Droits de l'Homme, Faculté de Droit, Université Montpellier, Bruselas: Bruylant Nemesis, 2008; ARNARDÓTTIR, O.M. Equality and NonDiscrimination under the European Convention on Human Rights, The Hague: Martinus Nijhoff Publishers, 2002.

${ }^{20}$ Sentencia E.B. v. Francia, de 22 de enero de 2008. Aun cuando en esta sentencia no se reconoce esta posibilidad de adopción, sí se señala que la denegación solo por razón de la orientación sexual de la peticionaria es una discriminación contraria al CEDH.

${ }^{21}$ Sentencia Kozak v. Polonia, de 2 de marzo de 2010 (subrogación del miembro supérstite de una pareja homosexual).

${ }^{22}$ Sentencia P.B. y J.S. v. Austria, de 22 de julio de 2010 (cobertura sanitaria de un seguro privado).

${ }^{23}$ Sentencia J.M. v. Reino Unido, de 28 de septiembre de 2010. 
El análisis de la posible existencia de discriminación, en los asuntos relacionados con la orientación sexual, se hará siguiendo el esquema clásico utilizado para otro tipo de asuntos, pero también aquí, asistiremos a una interesante evolución jurisprudencial. Se trata éste de un análisis desarrollado en los siguientes términos: una diferencia de trato es discriminatoria cuando no hay justificación objetiva y razonable para la misma, esto es, cuando no persigue una finalidad legítima, o cuando, aun existiendo ésta, no hay una razonable proporcionalidad entre los medios empleados y la finalidad buscada. Además, si estamos tratando diferenciaciones basadas en criterios sospechosos, suspect grounds ${ }^{24}$, como los expresamente citados en el art. 14 y también los añadidos por vía jurisprudencial, como ocurre con la orientación sexual, especiales razones muy motivadas deben aportarse para no considerar que se ha producido una discriminación.

Pues bien, en el análisis acerca de la existencia de una justificación objetiva y razonable, hemos asistido durante mucho tiempo a la afirmación por parte del TEDH de que las diferencias de trato basadas en la orientación sexual persiguen una finalidad legítima, cual puede ser la protección de menores de edad, como ocurre en Da Silva Mouta. El TEDH utiliza el criterio de la finalidad legítima casi vaciándolo de contenido, pues no relaciona el interés buscado, que puede considerarse siempre como legítimo, con los medios empleados para tal fin. Y es que un Estado miembro intentará aportar criterios de justificación de la diferencia de trato que puedan considerarse legítimos (el interés público, la protección de los menores de edad, la protección de la familia, etc...) y que en este tipo de análisis son fáciles de encontrar, al no considerar la idea de finalidad legítima como un concepto relacional, esto es, que relaciona el interés buscado con la medida que se adopta.

Podría decirse que esto es lo que en realidad se hace al realizar el análisis de proporcionalidad, pero se trata de conceptos distintos, y es que la protección frente a la discriminación ha sido puesta en marcha a través de la consideración como desproporcionadas de las medidas que introducen diferencias de trato en base a la orientación sexual. Es evidente la diferente perspectiva que supone la consideración de la proporcionalidad frente a la finalidad legítima: si establecemos que una diferenciación en base a un motivo concreto es desproporcionada, no negamos la posibilidad de que ese motivo pueda sustentar otro tipo de diferenciaciones, mientras que si rechazamos la legitimidad del mismo hecho de la diferenciación en base a un motivo concreto, estamos negando que ese mismo motivo pueda ser utilizado, sin aportar más razones, para otras diferenciaciones.

De esta manera, a nuestro entender, las alternativas correctas para realizar el análisis discriminatorio dentro del CEDH deberían ser las siguientes: o bien consideramos la

\footnotetext{
${ }^{24}$ Para un resumen del significado del término en la jurisprudencia del TEDH, ver el informe "The Prohibition of Discrimination under European Human Rights Law”, 2011, pg. 14-21, accesible en https://publications.europa.eu/en/publication-detail/-/publication/a77beb2e-329b-49a5-88168e45b059802a/language-en, consultado el 12 de marzo de 2019.
} 
finalidad legítima como un concepto que engloba los motivos de diferenciación (no es lo mismo decir que la finalidad es la protección de la infancia, que considerar que la finalidad es proteger a la infancia de la homosexualidad, por ejemplo), o introducimos el criterio de congruencia. Este criterio es el que permite relacionar el interés buscado en la diferenciación, con el tipo de medidas que se articulan para tal fin, de modo que lo que analizamos es la adecuación de uno con otras, y no si se trata de medidas demasiado gravosas o no (que es lo que teóricamente debe hacer un análisis de proporcionalidad). Sin embargo, ninguna de estas alternativas es la utilizada generalmente por el TEDH, que realiza el juicio acerca de la posible discriminación a través mayoritariamente de un estudio de proporcionalidad de las medidas.

Podríamos concluir, en este sentido, que la jurisprudencia en Da Silva Mouta, responde al menor grado posible de protección otorgable en base a la prohibición de discriminación del art. 14. Es una estrategia recurrente en el TEDH, que va ampliando el ámbito de protección de que se trate a lo largo del tiempo de manera progresiva. Y así, asistiremos más adelante, en la siguiente sentencia que vamos a ver, a la afirmación de la ilegitimidad de la diferenciación basada exclusivamente en la orientación sexual, esto es, al establecimiento de la orientación sexual como un auténtico suspect ground.

Pero antes de todo eso, la primera dificultad se evidencia en la consideración de cuándo estamos ante una diferencia de trato, y éste es un asunto de especial relevancia, ya que va a ser precisamente en este punto en el que la sentencia Taddeucci y McCall v. Italia ${ }^{25}$ supondrá un importantísimo cambio jurisprudencial, en el que observamos un nuevo giro interpretativo del contenido del derecho a la no discriminación que anuncia cambios muy importantes en el futuro ${ }^{26}$.

El asunto tiene como controversia de partida la situación de una pareja formada por dos hombres, uno de ellos italiano y su compañero de nacionalidad neozelandesa, que se ve compelida a abandonar Italia al ver rechazada la solicitud de residencia permanente por reunificación familiar del miembro de la pareja extracomunitario ${ }^{27}$. El argumento jurídico que apoya la no concesión de la residencia será que no se trata de una relación familiar de las que permiten la reunificación familiar, interpretando el Decreto Legislativo $\mathrm{n}^{\circ} 286$ de $1998^{28}$, en su artículo 29, y en referencia al concepto de “familiares” como solo

\footnotetext{
${ }^{25}$ Sentencia Taddeucci y McCall v. Italia, de 30 de junio de 2016.

26 Sobre la importancia de la prohibición de discriminación y su efecto expansivo respecto de otros derechos, ver JOHNSON, P. y FALCETTA, S. "Sexual orientación discrimination and Article 3 of the European Convention on Human Rights: developing the protection of sexual minorities”, European Law Review, 2018, in print.

27 Sobre la evolución normativa del reconocimiento de las parejas homosexuales en Italia, en relación al derecho europeo, ver MARINAI , S. "Recognition in Italy of Same-Sex Marriages Celebrated Abroad: The Importance of a Bottom-up Approach”, European Journal of Legal Studies, vol. 10, 2016-2017, pg. 10 ss. ${ }^{28}$ Decreto Legislativo 25 luglio 1998, n. 286, testo único delle disposizioni concernenti la disciplina dell'immigrazione e norme sulla condizione dello straniero (GU Serie Generale n. 191 del 18-08-1998 Suppl. Ordinario n. 139). El artículo 29 incluye también a los progenitores a cargo, aunque los antecedentes de la sentencia del TEDH op. cit. no hacen referencia a éstos.
} 
aplicable a los cónyuges, descendientes menores de edad, descendientes mayores de edad dependientes económicamente por motivos de salud, y otros familiares sin los mínimos apoyos en sus países de origen. Se negará por parte de los Tribunales italianos la posibilidad de ampliación del concepto a las parejas de hecho, quedando limitado a los matrimonios.

Lo primero que conviene señalar es que se trata de un asunto en el que intervendrán los colectivos LGBTI de forma muy activa ${ }^{29}$. Por una parte, el abogado de los recurrentes, el profesor Robert Wintemute ${ }^{30}$, es un importante defensor y activista de derechos humanos, y en particular de los derechos relacionados con la diversidad sexual, tanto en su faceta académica como en su labor como abogado asesor, habiendo colaborado de forma habitual y continuada con las organizaciones de defensa de los derechos LGBTI. Por otra parte, encontramos como amicus curiae o third-party interveners, presentando informes que cada vez resultan más relevantes en la conformación de la opinión del TEDH, a las siguientes organizaciones: International Commission of Jurists (ICJ), International Lesbian, Gay, Bisexual Trans and Intersex Association (ILGA) Europe, Network of European LGBT Families (NELFA) y European Commission on Sexual Orientation Law (ECSOL).

En segundo lugar, se trata del reconocimiento de la existencia de discriminación por orientación sexual entre parejas heterosexuales matrimoniales y parejas homosexuales que no pueden contraer matrimonio, por no existir esta posibilidad en el Estado miembro, una existencia de discriminación que había sido negada en la jurisprudencia anterior en varias ocasiones ${ }^{31}$. Y es precisamente en este ámbito en el que se producirá una modificación de la jurisprudencia del TEDH cuyas consecuencias están por ver, pero que se perfilan como muy prometedoras en la defensa de los derechos vinculados con la diversidad sexual. En concreto, más allá de los efectos positivos respecto del caso objeto de litigio, lo interesante es el nuevo enfoque en el análisis de la discriminación que se pone en práctica en esta sentencia.

Debemos recordar, a este respecto, que el TEDH ha mantenido hasta ahora la consideración de que el artículo 12 del CEDH “(...) is a lex specialis for the right to marry. It secures the fundamental right of a man and woman to marry and to found a family. Article 12 (...) enshrines the traditional concept of marriage as being between a man and a woman. While it is true that some Contracting States have extended marriage

\footnotetext{
${ }^{29}$ Estamos ante un nuevo ejemplo de los excelentes resultados de la aplicación de una muy inteligente estrategia de litigación.

${ }^{30}$ Robert Wintemute es profesor de Derechos Humanos en la King's College London, y colabora muy activamente tanto doctrinalmente como en su función de asesor jurídico para asuntos concretos con, entre otros, ILGA Europe. Se puede consultar parte de su trabajo en este sentido en https://www.ilgaeurope.org/search/node/wintemute (consultado el 12 de marzo de 2018).

${ }^{31}$ Sentencia Schalk y Kopf v. Austria, de 24 de junio de 2010; Gas y Dubois v. Francia, de 15 de marzo de 2012; X y Otros v. Austria, de 19 de febrero de 2013; y Aldeguer Tomás v. España, de 14 de junio de 2016. Sin embargo, sí que encontrará el TEDH discriminatoria la diferencia de trato entre parejas de hecho heterosexuales y homosexuales en la sentencia Vallianatos y Otros v. Grecia, de 7 de noviembre de 2013.
} 
to same-sex partners, Article 12 cannot be construed as imposing an obligation on the Contracting States to grant access to marriage to same-sex couples" 32 .

Efectivamente, el esquema de análisis que se va a utilizar es diferente a asuntos anteriores. Por una parte, empieza por considerar que tan discriminatorio puede ser tratar situaciones similares de modo distinto, como tratar situaciones distintas de modo similar $^{33}$. Esto da lugar al estudio del establecimiento de cuándo nos encontramos efectivamente antes situaciones distintas o similares, o lo que es lo mismo, a la valoración de los criterios de comparación, y su elección. Y va a ser en este momento del análisis en el que se haga especialmente patente que la aplicación de la cláusula antidiscriminatoria, ni es, ni debe ser neutra, esto es, es necesario elegir las situaciones que vamos a comparar desde la perspectiva de cuál es la finalidad que pretendemos conseguir con la protección frente a la discriminación ${ }^{34}$.

\footnotetext{
${ }^{32}$ Sentencia Hämäläinen v. Finlandia, de 16 de julio de 2014, p. 96.

${ }^{33}$ Un enfoque metodológico que ya fue establecido por el TEDH en la sentencia Hämäläinen, op. cit., y anteriormente, respecto de un asunto no relacionado con la diversidad sexual, en la sentencia Thlimmenos v. Grecia, de 6 de abril de 2000. Por su parte también ha sido utilizada por el Tribunal del Justicia de la Unión Europea, en relación a la orientación sexual, en la importante sentencia Jürgen Römer y Freie und Hansestadt Hamburg, de 10 de mayo de 2011, asunto C-147/08. Para un estudio de las diferencias en la aproximación al concepto de discriminación y su aplicación, entre ambos tribunales internacionales, ver PETERSEN, N. "The Principle of Non-discrimination in the European Convention on Human Rights and in EU Fundamental Rights Law”. En NAKANISHI Y. (eds) Contemporary Issues in Human Rights Law. Singapore: Springer, 2018, pg. 129-142. https://doi.org/10.1007/978-981-10-6129-5_7

${ }^{34}$ Encontramos un ejemplo en este sentido en la jurisprudencia del Tribunal de Justicia de la Unión Europea, en concreto, en las sentencias $P$ v. S y Cornwall County Council, de 30 de abril de 1996, asunto C-13/94 y Grant v. South-West Trains Ltd, de 17 de febrero de 1998, asunto C-249/96. Ambas sentencias dieron lugar en su momento a multitud de estudios doctrinales. Así, $P v$. $S$ fue tratado, entre otros, por ALONSO OLEA, M. "El Despido de un Transexual”, Actas de la Real Academia de Ciencias Morales y Políticas, 1997, pg. 237 ss.; MARISCAL DE GANTE, M. y LÓPEZ PASARO, E. “Transexualidad y Discriminación”, Revista Española de Derecho del Trabajo, no 97, 1999, pg. 60 ss.; MORALES ORTEGA, J.M. "Nuevos Fenómenos Discriminatorios: Homosexualidad y Transexualidad", Relaciones Laborales, no 18, 1999, pg. 55 ss.; VICENTE PALACIO, M.A. “Transexualidad y Contrato de Trabajo”, Tribuna Social, no 67, 1996, pg. 55 ss.; BARNARD, C. "P v. S: Kite Flying or a New Constitutional Approach?”, en DASHWOOD, A. y O'LEARY, S., The principle of Equal Treatment in EC Law, Sweet \& Maxwell, London, 1997, pg. 59 ss.; Idem, "The Principle of Equality in the Community Context: P, Grant, Kalanke and Marshall: Four Uneasy Bedfellows?" Cambridge Law Journal, no. 57, 1998, pg. 352 ss.; LOUX, A.C. "Is He Our Sister? Sex, Gender, and Transsexuals under European Law”, Web Journal of Current Legal Issues, vol. 3, 1997; WINTEMUTE, R. "Recognizing New Kinds of Direct Sex Discrimination: Transsexualism, Sexual Orientation and Dress Code”, Modern Law Review, vol. 60, 1997, en pg. 335 ss.; SKIDMORE, P. "Sex, Gender and Comparators in Employment and Discrimination”, Industrial Law Journal, vol. 26, 1997, pg. 51 ss. Por su parte Grant ha sido objeto de estudio por, entre otros, , BELL, M. "Shifting Conceptions of Sexual Discrimination at the Court of Justice: from P v. S to Grant v. SWT”, European Law Journal, vol. 5, 1999, pg. 63 ss.; BARNARD, C." "Some Are More Equal Than Others: the Decision of the Court of Justice in Grant vs. South-West Trains", Cambridge Journal of European Law, 1999, pg. 147 ss.; SPACKMAN, P. "Grant vs. South-West Trains: Equality for Same-sex Partners in the European Community”, American University Journal of International Law, no 12, 1997, pg. 1063 ss.; CONNOR, T. "European Community Discrimination Law: No Right to Equal Treatment in Employment in Respect of Same Sex Partner", European Law Review, n ${ }^{\circ}$ 4, 1998, pg. 378 ss.; HELFER, L. "European Court of Justice Decision Regarding Employment Discrimination on the Basis of Sexual Orientation", American Journal of International Law, vol. 93, nº 1, 1999, pg. 195 ss.; y BERTHOU, K. y MASSELO, A.“La CJE et les Couples Homosexuels”, Droit Social, ñ 1, 1998, pg. 20 ss. En España SANCHEZ-URAN AZAÑA, Y. "El Principio de No
} 
Aquí es donde realmente se va a producir un viraje interesantísimo en la jurisprudencia del TEDH. Y es que este Alto Tribunal va a considerar que comparar la situación de una pareja homosexual con la de una pareja heterosexual, ambas sin haber contraído matrimonio, y no tomar en consideración la imposibilidad legal de contraer matrimonio de las parejas homosexuales, supone de hecho tratar dos situaciones diferentes como si fueran iguales. Se trata de situaciones en las que lo relevante es la capacidad para contraer matrimonio de unas parejas respecto de otras, lo que las coloca en posiciones de partida distintas, y por tanto, establecer en este caso las mismas consecuencias jurídicas supone un trato diferenciado. Así, a efectos de conocer si estamos o no antes una posible discriminación, lo necesario es valorar las situaciones de una pareja homosexual que no puede contraer matrimonio con la de otra pareja heterosexual que sí puede. Establecida esta diferencia de trato, el TEDH pasa al segundo elemento de análisis, cual es conocer si la misma tiene una justificación objetiva y razonable, en los términos clásicos explicados supra.

Y de nuevo, en este punto, asistimos a un cambio de orientación muy importante, por cuanto este análisis se centra en la legitimidad de los fines perseguidos, y no en el nivel de proporcionalidad establecido entre aquellos y los medios utilizados. Así, el TEDH establece claramente que "[a]lthough protection of the traditional family may, in some circumstances, amount to a legitimate aim under Article 14, the Court considers that, regarding the matter in question here - granting a residence permit for family reasons to a homosexual foreign partner - it cannot amount to a 'particular convincing and weighty' reason capable of justifying, in the circumstances of the present case, discrimination on grounds of sexual orientation (...)”35. Se vincula de esta manera la valoración de la legitimidad de los fines buscados con los concretos motivos de diferenciación, de modo que la orientación sexual aparece como criterio, ahora sí, especialmente protegido, que condiciona la misma legitimidad de los fines buscados y también la elección de los elementos de comparación.

Resulta ésta una sentencia particularmente interesante por cuanto combina elementos ya tradicionales en el análisis de si existe o no discriminación en un determinado asunto, con un enfoque de los mismos más novedoso, que incide en cada elemento de estudio desde la óptica de una consideración finalista de la protección antidiscriminatoria, razón por la cual no resulta sorprendente desde este punto de vista que finalmente se considere que nos encontramos ante una discriminación indirecta aun cuando, formalmente, se ha utilizado un enfoque de valoración tradicionalmente ligado a la discriminación directa,

Discriminación Sexual en el Derecho Social Comunitario: ¿Avance Sustancial del Tratado de Ámsterdam?”, en V.V.A.A., Estudios de Derecho del Trabajo y de la Seguridad Social en Homenaje al Profesor Juan Antonio Sagardoy Bengoechea, Madrid: Servicio de Publicaciones de la Facultad de Derecho de la Universidad Complutense, 1999, pg. 363 ss.; MORALES ORTEGA, J.M. "Nuevos Fenómenos Discriminatorios..., op. cit. y GONZÁLEZ VEGA, J. "Buscando en la Caja de Pandora: el Derecho Comunitario ante la Discriminación por Razones de Orientación Sexual”, La Ley-Unión Europea, nº 4522, 1998.

${ }^{35}$ Sentencia Taddeucci..., op. cit., ${ }^{\circ} 79$. 
pero con las variaciones que acabamos de $\operatorname{apuntar}^{36}$. Será precisamente esta visión de la prohibición de discriminación como elemento de transformación social de la situación de grupos desfavorecidos la que marque todo el análisis antidiscriminatorio en este asunto.

La condena a Italia, en estas circunstancias, resulta inevitable ${ }^{37}$.

\section{La respuesta del TJUE: Coman.}

Diferente va a ser la respuesta a una situación muy parecida que ofrecerá el TJUE ${ }^{38}$.

Es cierto que nos encontramos ante dos Tribunales europeos con una posición radicalmente distinta en relación a sus funciones y objetivos. Mientras el TEDH tiene como cometido la garantía de los derechos humanos derivados del CEDH y de sus protocolos, y por tanto, es sustancialmente un Tribunal de protección de derechos humanos, en el caso del TJEU nos encontramos ante un órgano con una posición jurídica más compleja, en relación a los derechos fundamentales establecidos en la Carta de Derechos Fundamentales de la UE y en relación también a los principios generales del derecho de la UE, entre los que ocupa un lugar importante el principio de igualdad. Y así, el enfoque que este último Tribunal tiene que adoptar, viene en gran medida comprometido por los elementos esenciales del derecho de la UE, que a día de hoy sigue profundamente marcado por las libertades de circulación como garantía de un espacio económico común.

Esta circunstancia va a resultar determinante para entender la posición del TJUE en la materia que nos ocupa, y en general en relación a la implementación de los derechos fundamentales de la UE, pues dependiendo del grado de intervención en el derecho interno de los Estados miembros que supongan sus decisiones, optará por una mayor contundencia o por el contrario, se mantendrá en el mínimo grado de protección de los derechos que sea compatible con la normativa comunitaria. Así, cuando se trata de incidir en materia que claramente entra dentro del ámbito competencial de la UE, el TJUE ha resultado tremendamente activo, y sin embargo, cuando nos encontramos ante el efecto

\footnotetext{
${ }^{36}$ Así, el TEDH afirma que "(...) where a general policy or measure has disproportionately prejudicial effects on a particular group, it is not excluded that this may be considered as discriminatory notwithstanding that it is not specifically aimed or directed at that group and there is no discriminatory intent. Such a situation may amount to 'indirect discrimination'”. Sentencia Taddeucci..., op. cit., n ${ }^{\circ} 67$.

${ }^{37} \mathrm{Y}$ ello a pesar del importante reconocimiento de las parejas homosexuales como "grupo social" por parte del Tribunal Constitucional italiano, en su sentencia $\mathrm{n}^{\circ} 138$ de 15 de abril de 2010, en la que, sin embargo, como se resume en Taddeucci, se compara la situación de las parejas del mismo sexo con las heterosexuales no ligadas por vínculo matrimonial.

${ }^{38}$ Sentencia Relu Adrian Coman y otros v. Inspectoratul General pentru Imigrări y Ministerul Afacerilor, de 5 de junio de 2018, asunto C-673/16.
} 
expansivo a otras materias propias del derecho nacional, parece necesitar seguir en cierta medida la estela de la jurisprudencia del TEDH ${ }^{39}$.

En materia de vida privada y familiar, matrimonio y discriminación por orientación sexual, de nuevo resulta imposible en un trabajo de estas características hacer mención a toda la jurisprudencia del TJUE que, aunque mucha menos que en el caso del TEDH, es numerosa. Vamos por tanto a seleccionar algunas sentencias que resultan especialmente reveladoras de la posición del TJUE en estas materias.

Para empezar, en relación a la forma de acometer asuntos que tocan de lleno el ámbito competencial del derecho de la UE en los que la interpretación de los derechos fundamentales es un elemento esencial, asistiremos a una importante protección del colectivo LGBTI en la sentencia Tadao Maruko y Versorgungsanstalt der deutschen Bühnen $^{40}$, en un asunto relacionado con la aplicación de la Directiva 2000/78, de igualdad de trato en el empleo y la ocupación ${ }^{41}$. Se trata de una Directiva que tiene por objeto la protección frente a motivos discriminatorios que se enumeran en su artículo 1 y entre los que expresamente se encuentra la orientación sexual ${ }^{42}$.

En este asunto, frente a la reclamación de la pareja masculina de un trabajador al que se le ha denegado la pensión de supervivencia a la muerte de éste, el TJUE, tras afirmar la aplicabilidad de la Directiva en este caso, establece como criterio competencial que "[s]i bien el estado civil y las prestaciones que de él dependen son materias comprendidas dentro de la competencia de los Estados miembros, competencia que el Derecho comunitario no restringe, se ha de recordar, sin embargo, que, en el ejercicio de dicha competencia, los Estados miembros deben respetar el Derecho comunitario, en especial las disposiciones relativas al principio de no discriminación”43. Establecida la

\footnotetext{
39 Ver acerca de la valoración de la acción de estos Tribunales en relación a la orientación sexual, WINTEMUTE, R. “In Extending Human Rights, which European Court is Substantively 'Braver' and Procedurally 'Fitter'? The Example of Sexual Orientation and Gender Identity Discrimination" in MORANO-FOADI, S. y VICKERS, L. (eds.), Fundamental Rights in the EU: A Matter for Two Courts, Oxford: Hart Publishing, 2015.

${ }^{40}$ Sentencia Tadao Maruko y Versorgungsanstalt der deutschen Bühnen, de 1 de abril de 2008, asunto C267/06.

${ }^{41}$ Directiva 2000/78/CE del Consejo, de 27 de noviembre de 2000, relativa al establecimiento de un marco general para la igualdad de trato en el empleo y la ocupación.

42 Sobre el objeto y alcance de esta Directiva, ver por todos, CHACARTEGUI JÁvEGA, C. Discriminación y Orientación Sexual del Trabajador, Valladolid: Lex Nova, 2001; Ibídem, "La Tutela de la Discriminación por la Orientación Sexual del Trabajador en el Ordenamiento Social Comunitario”, en ASOCIACIÓN ESPAÑOLA DE DERECHO DEL TRABAJO Y DE LA SEGURIDAD SOCIAL, La Igualdad ante la Ley y la No Discriminación en las Relaciones Laborales: XV Congreso Nacional de Derecho del Trabajo y de la Seguridad Social, Madrid: Ministerio de Trabajo y Asuntos Sociales, 2005, pg. 537 ss.; RIVAS VAÑÓ, A. y RODRÍGUEZ-PIÑERO ROYO, M. “Orientación Sexual y Derecho Europeo”, en FERNÁNDEZ LIESA, C. y MARIÑO MENÉNDEZ, F. La Protección de las Personas y Grupos Vulnerables en el Derecho Europeo, Madrid: Ministerio de Asuntos Sociales, 2001, pg. 293 ss.; RIVAS VAÑÓ, A. "La Prohibición de Discriminación por Orientación Sexual en la Directiva 2000/78”, Temas Laborales, $\mathrm{n}^{\circ}$ 59, 2001, pg. 193 ss.; MEENAN, H. (ed), Equality Law for an Enlarged Union: Understanding the Article 13 Directives, Cambridge: Cambridge University Press, 2007.

${ }^{43}$ Sentencia Tadao Maruko..., op. cit., n ${ }^{\circ} 59$.
} 
habilitación competencial, el TJUE deja en manos del juzgador nacional la consideración de si la situación de una pareja homosexual inscrita es similar a la de un matrimonio heterosexual, y en caso de que así se considere, concluye con la afirmación de que estamos ante un caso de discriminación directa, por cuanto a situaciones sustancialmente iguales se les está dispensando un trato desigual.

Conviene detenerse un momento en este punto, ya que la consideración de este trato como discriminación directa, lejos de constituirse en una protección agravada de la orientación sexual, comprende en realidad un menor grado de protección que si se hubiera utilizado el concepto de discriminación indirecta (como sí hace en Taddeucci el TEDH, como acabamos de ver). Y ello por varios motivos, no escapa a este análisis el que se derive a las autoridades nacionales la consideración de si, en el caso de las parejas homosexuales inscritas, nos encontramos ante situaciones similares a las de las parejas heterosexuales matrimoniales. Esto permite, por parte de la autoridad nacional, elegir los elementos de comparación ${ }^{44}$, y sobre esa base, en buena medida, decidir a priori cuál va a ser la conclusión respecto de si ha habido trato discriminatorio. Pero es que, en segundo lugar, la consideración de la diferencia de trato en términos de discriminación directa, implica además, limitar las consecuencias jurídicas tan solo a situaciones equiparables a la aquí estudiada, por cuanto no focaliza el análisis en las posibles consecuencias negativas para el grupo social vulnerable, sino tan solo en la imposibilidad de justificar una diferencia de trato concreta, en relación con otra situación concreta comparable, en términos de no discriminación. De este modo, todas las posibilidades de ampliación de la protección antidiscriminatoria que el concepto de discriminación indirecta confiere, se pierden en esta ocasión ${ }^{45}$.

Sin embargo, también son importantes las ventajas que una aproximación a este tipo de asuntos desde la consideración de los mismos como discriminación directa tiene, y en concreto, para empezar, la rotunda afirmación de que “(...) aunque una diferencia de trato no se base expresamente en la orientación sexual de los trabajadores, sino en la situación matrimonial de éstos, seguirá constituyendo una discriminación directa, habida cuenta de que, al estar reservado el matrimonio a las personas de distinto sexo, los trabajadores homosexuales se verán en la imposibilidad de cumplir el requisito necesario para obtener

\footnotetext{
${ }^{44}$ Si bien en la sentencia Römer..., op. cit., el TJUE es más incisivo, empujando a las autoridades nacionales a considerar como situaciones comparables las de las parejas homosexuales de hecho y las de las parejas heterosexuales matrimoniales.

${ }^{45}$ Sobre esta idea, ver BELL, M. "Gender identity and sexual orientation: alternative pathways in EU equality law”, The American Journal of Comparative Law, vol. 60, n 1, 2012, pg. 127 ss. No compartimos su argumentación que considera el concepto de discriminación directa como una manera de aplicación de la igualdad formal, por cuanto se trata de un instrumento de transformación social que precisamente incide sobre situaciones de desigualdad sustantiva, pero sí resulta muy interesante el análisis que realiza de las posibilidades que amplía el concepto de discriminación indirecta. En contra, y afirmando la utilidad del análisis en términos de discriminación directa, MULDER, J. "Dignity or discrimination: what paves the road towards equal recognition of same-sex couples in the European Union?” Journal of Social Welfare and Family Law, vol. 40, n 1, 2018, pg. 129 ss.
} 
la ventaja reclamada" ${ }^{46}$. Además, respecto de la aplicación de la Directiva en la que se enmarcan estos casos, el enfoque de la discriminación directa permite un escrutinio más estricto respecto de las posibles limitaciones y excepciones a la prohibición de discriminación. Así, "en la medida en que la discriminación producida es directa, no podrá justificarse por una 'finalidad legítima', en el sentido del artículo 2, apartado 2, letra b), de la Directiva 2000/78 — puesto que esta disposición sólo se refiere a la discriminación indirecta-, sino únicamente por alguno de los motivos contemplados en el artículo 2, apartado 5, de la misma Directiva, a saber, la seguridad pública, la defensa del orden y la prevención de infracciones penales, la protección de la salud y la protección de los derechos y libertades de los ciudadanos" ${ }^{47}$. Resultando además, que cuando se invoquen estos últimos motivos, deberán interpretarse éstos en sentido estricto.

Va a ser muy distinto el enfoque elegido por el TJUE en el asunto Coman ${ }^{48}$, un asunto que plantea un problema casi idéntico al resuelto por el TEDH en Taddeucci, dos años antes. Efectivamente nos encontramos ante la situación de un nacional rumano que ve denegado el permiso de residencia en Rumanía, para su cónyuge masculino, nacional de Estados Unidos. La pareja contrajo matrimonio en Bélgica. Estamos así ante una pareja del mismo sexo en el que uno de los miembros es nacional de un tercer Estado, que contrae matrimonio en un Estado miembro distinto del de la nacionalidad de ninguno de ellos y que pretende el reconocimiento de este matrimonio, a efectos de la concesión de un permiso de residencia de larga duración, en el Estado miembro del que es nacional uno de los cónyuges. El Tribunal Constitucional rumano eleva una cuestión prejudicial ${ }^{49}$ al

\footnotetext{
46 Sentencia Frédéric Hay v Crédit agricole mutuel de Charente-Maritime et des Deux-Sèvres, de 12 de diciembre de 2013, asunto C-267/12, en $\mathrm{n}^{0}$ 44. Un comentario de esta sentencia en MOLINA NAVARRETE, C. "Diversidad de Orientación Sexual y Principio de Igualdad de Trato Laboral: ¿El Fin de la Diferencia entre Parejas de "Hecho" y de "Derecho"? (Comentario a la Sentencia del Tribunal de Justicia de la Unión Europea, de 12 de diciembre de 2013, asunto n C-267/12)”, Estudios Financieros. Revista de Trabajo y Seguridad Social, no 371, 2014, pg. 171 ss.

47 Sentencia Frédéric Hay..., op. cit., $\mathrm{n}^{\circ} 45$.

48 Comentarios a esta sentencia pueden encontrarse en GYENEY, L. "Same sex couples' right to free movement in light of member States' national identities” Iustum Aequum Salutare, XIV, 2018, pg. 149 ss.; HAMILTON, F. "The expanding concept of EU citizenship free movement rights and the potential positive impact this has for same-sex couples relocating across borders”, Famity Law, 2018; PAPADOPOULOU, G. "Sexual orientation and gender identity law in the European Union and its Court of Justice", en ZIEGLER, A.R. (ed.) Oxford Handbook of International LBGTI Law-Sexual Orientation, Gender Identity, Gender Expression and Sex Characteristics (SOGIESC) Law from an International-Comparative Perspective, Oxford: Oxford University Press, 2019; STEHLÍK, V. "The CJEU crossing the Rubicon on the same-sex marriages? Commentary on Coman case”, International and Comparative Law Review, vol. 18, $\mathrm{n}^{\circ}$ 2, 2018, pg. 85 ss. DOI: 10.2478/iclr-2018-0039; STOPPIONI, E. "Une analyse critique de l'arrêt Coman: déconstruction de la consécration de l’obligation de reconnaissance du droit de séjour du conjoint homosexuel", European Papers, European Forum, 27 de febrero de 2019, pg. 1 ss. DOI: 10.15166/24998249/280; WAALDIJK, K. "The gender-neutrality of the international right to marry: Same-sex couples may still be excluded from marriage, but their exclusion - and their foreign marriages - must be recognized”, en ZIEGLER, A.R. International LGBTI, forth coming; ÁLVAREZ GONZÁLEZ, S. “Matrimonio entre personas del mismo sexo para toda la UE? A propósito de las conclusiones del Abogado General en el asunto Coman”, La Ley Unión Europea, n 56, 2018.

${ }^{49}$ En este asunto se personarán, además de los afectados, bajo la dirección letrada, entre otros, del profesor Wintemute (que también participó en Taddeucci), en defensa de los derechos de las parejas del mismo sexo,
} 
TJUE acerca de la inclusión de las parejas del mismo sexo en alguno de los supuestos que protege la Directiva 2004/38, sobre circulación de personas en el territorio de la UE ${ }^{50}$. La primera dificultad tendrá que ver con el derecho aplicable a este asunto, afirmando el TJUE que la Directiva de la que hablamos no es de aplicación directa al no tratarse de un ciudadano de la UE que se desplaza a otro Estado miembro y solicita un permiso para su familia, sino que es un nacional en su propio Estado el que lo hace. Establece el TJUE que la norma aplicable es el artículo 21 del Tratado de Funcionamiento de la Unión Europea (en adelante TFUE), que reconoce el derecho de todo ciudadano de la Unión a circular y residir libremente en el territorio de los Estados miembros. Pero en relación a cómo se concretan los requisitos para ejercer este derecho, sí será de aplicación por analogía la mencionada Directiva, puesto que no puede ser más gravosa la situación de un nacional de un Estado miembro en su propio Estado que la de un ciudadano que se traslada a otro. Resulta en este sentido muy importante el hecho de que la convivencia familiar de esta pareja se había producido en otro Estado de la UE, ya que si no se reconociera el derecho de reagrupación familiar “(...) la inexistencia de tal derecho de residencia derivado podría disuadir al ciudadano de la Unión de salir del Estado miembro del que es nacional para ejercer su derecho de residencia, en virtud del artículo 21 TFUE, apartado 1, en otro Estado miembro, ante la incertidumbre de si podrá continuar, en su Estado miembro de origen, una convivencia familiar desarrollada o consolidada en el Estado miembro de acogida" 51.

Pero lo importante a los efectos del asunto que estamos tratando es la perspectiva de análisis de esta controversia, que lejos de lo que pudiera parecer en un principio, no va a pivotar en torno a la protección del derecho a la vida familiar y a la prohibición de discriminación por orientación sexual, sino que va a centrarse en asegurar las condiciones para la libertad de circulación de personas, en consonancia, quizás, con el papel del TJUE de última garantía de aplicabilidad del Derecho de la UE, que sigue siendo fundamentalmente un derecho de protección de un mercado común, en detrimento del nuevo papel de garante de los derechos fundamentales reconocidos en la Carta de Derechos Fundamentales de la Unión Europea (en adelante CDF).

En efecto, todo el análisis de la situación planteada gira en torno a los posibles obstáculos que no conceder el permiso de residencia al ciudadano del tercer Estado, puede suponer para los ciudadanos de la UE. En ningún momento de la sentencia se utiliza como argumento el derecho a la no discriminación por orientación sexual ${ }^{52}$, ni tan siquiera

\footnotetext{
la asociación Asociaţia Accept (con la misma dirección letrada), el Consiliul Naţional petru Combaterea Discriminării, y el Gobierno de los Países Bajos, y en contra los Gobiernos de Rumanía, Letonia, Hungría y Polonia.

50 Directiva 2004/38/CE del Parlamento Europeo y del Consejo, de 29 de abril de 2004, relativa al derecho de los ciudadanos de la Unión y de los miembros de sus familias a circular y residir libremente en el territorio de los Estados miembros.

${ }^{51}$ Sentencia Coman..., n ${ }^{\circ} 24$.

52 Argumento que sí había sido aportado por las partes, tanto por la defensa del señor Coman como por parte del Tribunal Constitucional rumano.
} 
cuando se interpreta el sentido de "cónyuge" de la Directiva ${ }^{53}$. El TJUE considera que “(...) el concepto de 'cónyuge' en el sentido de la Directiva 2004/38 es neutro desde el punto de vista del género y puede, por tanto, incluir al cónyuge del mismo sexo del ciudadano de la Unión de que se trate" ${ }^{24}$, sin limitaciones ni remisiones al derecho nacional, por lo que un Estado miembro no puede invocar su Derecho nacional para oponerse a la concesión de un permiso de residencia a un nacional de un tercer Estado que haya contraído matrimonio con un ciudadano de la Unión del mismo sexo en otro Estado miembro.

Tiene especial cuidado el TJUE en aclarar que “(...) el estado civil de las personas, en el que se incluyen las normas relativas al matrimonio, es una materia comprendida dentro de la competencia de los Estados miembros, competencia que el Derecho de la Unión no restringe (...) Los Estados miembros disponen de ese modo de la libertad de contemplar o no el matrimonio entre personas del mismo sexo" 55 pero en el ejercicio de esta competencia deben respetar el Derecho de la Unión, y en particular la libertad, reconocida a todo ciudadano de la Unión, de circular y residir en el territorio de los Estados miembros. Y será ésta la razón última que determinará que Rumanía tiene la obligación de conceder un permiso de residencia de larga duración al cónyuge masculino de su ciudadano nacional.

Tan solo vemos tímidamente la aparición de cierta perspectiva de derechos fundamentales de la UE en esta sentencia en la negación de la validez de los motivos que el Estado arguye para negar tal concesión, que fundamenta esta restricción a la libre circulación de las personas en razones de orden público y de identidad nacional. Y aún aquí, aparece como base argumentativa de segundo orden, siendo el primer argumento la nula incidencia que la concesión del permiso de residencia en estos supuestos supone para el matrimonio tradicional en los Estados miembros que niegan la posibilidad de otras formas de matrimonio. Así, el TJUE explica que “(...) una medida nacional que pueda obstaculizar el ejercicio de la libre circulación de las personas solo puede justificarse si es conforme con los derechos fundamentales garantizados por la Carta, cuyo respeto garantiza el Tribunal de Justicia" ${ }^{56}$, y aún apelando a esta necesidad de conformidad, los derechos que considera pueden estar en peligro son el derecho a la vida privada y familiar, y no, o al menos no se hace mención a ello, el derecho a la no discriminación por orientación sexual, que sin embargo, parecería un elemento indispensable del análisis de la situación planteada.

Resulta necesario, en este contexto, preguntarse por la ausencia total en esta sentencia de cualquier referencia a la prohibición de discriminación por orientación sexual, recogida en el artículo 21 de la CDF, así como, en relación a la Directiva de aplicación

\footnotetext{
${ }^{53}$ Algo que sí hace el Abogado General en sus conclusiones en este asunto.

${ }^{54}$ Sentencia Coman..., n ${ }^{\circ} 34$.

55 Ibídem, n 37.

${ }^{56}$ Ibídem, no 47.
} 
por analogía, en su considerando $31^{57}$. Es difícil dar una respuesta a esta cuestión, pero podemos argumentar, siempre dentro del terreno de la especulación, que el TJUE ha

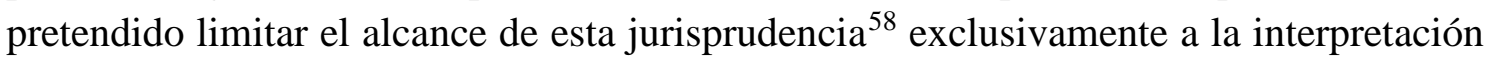
de la Directiva controvertida, no permitiendo sacar consecuencias distintas del concreto significado que el matrimonio entre personas del mismo sexo tiene a efectos de la libre circulación de personas. Y esto no es más que la consecuencia de la indecisión que el propio legislador, en el momento de elaboración de la Directiva ya mostró. En efecto, como apunta el Abogado General en sus conclusiones sobre este asunto, ya en los trabajos preparatorios, el Parlamento solicitó que se mencionara la indiferencia del sexo de la persona mediante el añadido de la expresión "independientemente de su sexo, conforme a la correspondiente legislación nacional”, algo que finalmente el Consejo de la UE rechazó. Como bien dice el Abogado General Wathelet, "está claro que el legislador de la Unión era perfectamente consciente de la controversia que podía existir sobre la interpretación del término 'cónyuge' no definido de otro modo. Pues bien, decidió no precisar este concepto, ya para limitarlo al matrimonio heterosexual o, por el contrario, ya para referirse al matrimonio entre personas del mismo sexo - a pesar de que la Comisión señaló expresamente la posibilidad de una evolución a este respecto-. Esta reserva de la Comisión es esencial, excluye que el sentido del concepto de 'cónyuge' quede definitivamente fijado y al margen de la evolución de la sociedad"59.

Si se hubiera introducido el análisis de la posible discriminación por orientación sexual, estaríamos ante un escenario en el que vaciamos de contenido, como de hecho sucede en Taddeucci, a la institución del matrimonio entendida como una institución especial, con características propias que permiten una distinción respecto de otras formas de relaciones sentimentales y ello supondría un activismo judicial del que el TJUE parece no querer hacer uso en este caso, aún cuando nos encontremos ante argumentos de peso que lo aconsejen.

Sí conviene destacar un efecto paradójico, no sabemos si voluntario o no, de la sentencia Coman, y es que el TJUE señala que los derechos garantizados en el artículo 7 de la CDF (derecho a la vida privada y familiar), tienen el mismo sentido y alcance que los garantizados en el artículo 8 del CEDH y se remite a la jurisprudencia del TEDH a este respecto. Como bien recuerda el Abogado General en sus conclusiones "El TEDH también ha confirmado que el artículo 8 del CEDH imponía a los Estados la obligación

\footnotetext{
${ }^{57}$ Que dice: "La presente Directiva respeta los derechos y libertades fundamentales y observa los principios reconocidos, en particular, por la [Carta]. De conformidad con la prohibición de discriminación que contiene la Carta, los Estados miembros deben aplicar las disposiciones de la misma sin discriminar entre los beneficiarios de la presente Directiva por razones como el sexo, raza, color, origen étnico o social, características genéticas, lengua, religión o convicciones, opiniones políticas o de otro tipo, pertenencia a una minoría nacional, patrimonio, nacimiento, discapacidad, edad u orientación sexual”.

${ }^{58} \mathrm{Al}$ modo en que el Magistrado Sicilianos pretende, en su voto particular parcialmente discrepante, en Taddeucci, limitar el alcance de la protección otorgada al análisis de la vulneración del derecho a la vida privada y familiar, sin incorporar un análisis sobre discriminación que implica mayores consecuencias.

${ }_{59}$ Conclusiones del Abogado General Melchior Wathelet, presentadas el 11 de enero de 2018 en el asunto C-673/16, en n 52.
} 
de ofrecer a las parejas homosexuales la posibilidad de obtener un reconocimiento legal y la protección jurídica de su pareja" ${ }^{60}$. Pues bien, si no se hace este reconocimiento siquiera parcial, como ocurre en este caso, los Estados miembros que en esta situación se niegan a cumplir el CEDH, tendrán que asumir la obligación a través del derecho de la UE de reconocer los efectos del matrimonio homosexual celebrado en otro Estado miembro. En cierta medida, el TJUE castiga la inactividad de los Estados miembros que no hacen ningún tipo de reconocimiento jurídico de las parejas homosexuales, imponiendo en estas circunstancias la obligación de reconocimiento del matrimonio homosexual celebrado en otro Estado miembro, siquiera sea a efectos de libertad de circulación. Se trata de una manera indirecta, seguramente no necesariamente buscada, de colaboración entre Tribunales en la consecución de la asunción estatal de sus obligaciones en materia de respeto de derechos humanos.

\section{Conclusiones.}

Hemos asistido a la aproximación a dos asuntos muy parecidos desde ópticas completamente distintas, por parte de los Tribunales supranacionales europeos. Observamos la importancia de afrontar la situación de colectivos excluidos tradicionalmente del disfrute de ciertos derechos desde la perspectiva de la prohibición de discriminación como elemento esencial de análisis que permite hacer frente, desde la conexión de unos derechos con otros, a multitud de situaciones de vulneración de derechos humanos. Vemos también cómo la utilización de criterios de interpretación pretendidamente neutros, en el sentido de no conectados con otros valores del ordenamiento jurídico, implica una limitación del contenido de la protección, que debe entonces ser otorgada caso a caso, situación a situación, no pudiendo extrapolar las consecuencias de una determinada conclusión jurisprudencial a la interpretación de otras normas.

En los casos que hemos analizado, solo eludiendo la perspectiva de análisis de derechos humanos se puede llegar a la limitación de la equiparación de matrimonio homo y heterosexual, siquiera sea a efectos de la libre circulación. Y es que tan solo si privamos de contenido normativo a la situación que se valora, convirtiendo en un problema de meros obstáculos regulatorios para la libre circulación, podemos sostener la singularidad del matrimonio heterosexual clásico. Singularidad que, desde una perspectiva de derechos humanos, necesariamente cede frente a la necesidad de no discriminar por orientación sexual (y no solo, también ha sufrido una importante transformación en los derechos y deberes de los cónyuges cuando de no discriminación por género se trata). Y ello porque, como ya se ha apuntado en el análisis de Taddeucci, asistimos al argumento circular de que el matrimonio es una institución peculiar por cuanto es de carácter heterosexual y esta heterosexualidad es lo que le confiere esa peculiaridad. Desde el momento en que

${ }^{60}$ Ibídem, no 62. Se refiere a la sentencia Taddeucci..., n 56. 
despojamos a la institución matrimonial de componentes religiosos y le otorgamos características y validez civil, y más aún, desde que se inserta en un sistema de derechos humanos, necesariamente va a ser objeto de transformaciones. Este proceso transformativo va a resultar especialmente importante cuando se reconoce la prohibición de discriminación por orientación sexual, respecto de la cual mantiene su vigencia a modo de excepción, con un marcado carácter de temporalidad, que solo se justifica por la necesidad de ofrecer un margen de apreciación a los Estados para que vayan asumiendo la evolución de la institución que se avecina.

Solo desde esta última posición se puede entender la postura del TJUE, que está menos familiarizado si se quiere con un activismo judicial de incidencia masiva en los ordenamientos jurídicos de los Estados miembros, que el TEDH, aun cuando este último sea más dependiente de la voluntad de los Estados miembros de asumir sus obligaciones respecto del CEDH.

\section{BIBLIOGRAFÍA}

ADAM, B.D. The Rise of a Gay and Lesbian Movement, New York: Twayne Publishers, 1995.

ADAM, B.D, DUYVENDAK, J.W. y KROUWEL, A. (eds.) The Global Emergence of Gay and Lesbian Politics: National Imprints of a Worldwide Movement, Philadelphia: Temple University Press, 1999.

ALONSO OLEA, M. "El Despido de un Transexual”, Actas de la Real Academia de Ciencias Morales y Políticas, 1997, pg. 237 ss.

ÁLVAREZ GONZÁLEZ, S. “¿Matrimonio entre personas del mismo sexo para toda la UE? A propósito de las conclusiones del Abogado General en el asunto Coman”, La Ley Unión Europea, n 56, 2018.

ARNARDÓTTIR, O.M. Equality and Non-Discrimination under the European Convention on Human Rights, The Hague: Martinus Nijhoff Publishers, 2002.

BAMFORTH, N., MALIK, M. y O’CINNEIDE, C. Discrimination Law: Theory and Context, Text and Materials, Londres: Sweet and Maxwell, 2008.

BARNARD, C. "P v. S: Kite Flying or a New Constitutional Approach?”, en DASHWOOD, A. y O'LEARY, S., The principle of Equal Treatment in EC Law, Sweet \& Maxwell, London, 1997, pg. 59 ss.

BARNARD, C. "The Principle of Equality in the Community Context: P, Grant, Kalanke and Marshall: Four Uneasy Bedfellows?” Cambridge Law Journal, no. 57, 1998, pg. 352 ss.

BARNARD, C. "Some Are More Equal Than Others: the Decision of the Court of Justice in Grant vs. South-West Trains”, Cambridge Journal of European Law, 1999, pg. 147 ss. 
BELL, M., "Shifting Conceptions of Sexual Discrimination at the Court of Justice: from P v. S to Grant v. SWT”, European Law Journal, vol. 5, 1999, pg. 63 ss.

BELL, M. "Gender identity and sexual orientation: alternative pathways in EU equality law”, The American Journal of Comparative Law, vol. 60, n 1, 2012, pg. 127 ss.

BERTHOU, K. y MASSELO, A. “La CJE et les Couples Homosexuels”, Droit Social, n ${ }^{\circ}$ 1, 1998, pg. 20 ss.

BERTOLINO, R. "La cultura moderna de los derechos y la dignidad del hombre", Derechos y Libertades, $\mathrm{n}^{\circ}$ 7, 1999, pg.131.

CHACARTEGUI JÁVEGA, C. Discriminación y Orientación Sexual del Trabajador, Valladolid: Lex Nova, 2001.

CHACARTEGUI JÁVEGA, C. "La Tutela de la Discriminación por la Orientación Sexual del Trabajador en el Ordenamiento Social Comunitario”, en ASOCIACIÓN ESPAÑOLA DE DERECHO DEL TRABAJO Y DE LA SEGURIDAD SOCIAL, La Igualdad ante la Ley y la No Discriminación en las Relaciones Laborales: XV Congreso Nacional de Derecho del Trabajo y de la Seguridad Social, Madrid: Ministerio de Trabajo y Asuntos Sociales, 2005, pg. 537 ss.

CONNOR, T. "European Community Discrimination Law: No Right to Equal Treatment in Employment in Respect of Same Sex Partner”, European Law Review, n 4, 1998, pg. 378 ss.

GONZÁLEZ VEGA, J. "Buscando en la Caja de Pandora: el Derecho Comunitario ante la Discriminación por Razones de Orientación Sexual”, La Ley-Unión Europea, nº 4522, 1998.

GYENEY, L. 'Same sex couples' right to free movement in light of member States' national identities” Iustum Aequum Salutare, XIV, 2018, pg. 149 ss.

HAMILTON, F. "The expanding concept of EU citizenship free movement rights and the potential positive impact this has for same-sex couples relocating across borders”, Famity Law, 2018.

HELFER, L.R. “Consensus, Coherence and the European Convention on Human Rights”. Cornell International Law Journal, vol. 26, 1993, pg. 133 ss.

HELFER, L. "European Court of Justice Decision Regarding Employment Discrimination on the Basis of Sexual Orientation”, American Journal of International Law, vol. 93, nº 1, 1999, pg. 195 ss.

HELFER, L. y VOETEN, E. "International Courts as Agents of Legal Change: Evidence from LGBT Rights in Europe”. International Organization, vol. 68, n 1, 2014, pg. 77110. doi: $10.1017 /$ S0020818313000398

HENDERSON, L. M., A New Protocol for Equality: A New Vehicle Toward Gay Rights as Human Rights? Mayo, 2010. Accesible en SSRN: https://ssrn.com/abstract=1638385 or http://dx.doi.org/10.2139/ssrn.1638385. HODSON, L. NGOs and the Struggle for Human Rights in Europe, Oxford: Hart Publishing, 2011.

ILGA-Europe, Annual Review of the Human Rights Situation of Lesbian, Gay, Bisexual, Trans and Intersex People, Brussels: ILGA-Europe, 2019. 
JOHNSON, P. Homosexuality and the European Court of Human Rights, Oxon: Routledge, 2013.

JOHNSON, P. y FALCETTA, S. "Sexual orientación discrimination and Article 3 of the European Convention on Human Rights: developing the protection of sexual minorities”, European Law Review, 2018, in print.

LOUX, A.C. "Is He Our Sister? Sex, Gender, and Transsexuals under European Law", Web Journal of Current Legal Issues, vol. 3, 1997.

LOUX, A.C. "Losing the Battle, Winning the War: Litigation Strategy and Pressure Group Organization in the Era of Incorporation”, King's Law Journal, vol. 11, n 1, 2000, pg. 90-104.

MARINAI , S. "Recognition in Italy of Same-Sex Marriages Celebrated Abroad: The Importance of a Bottom-up Approach”, European Journal of Legal Studies, vol. 10, 20162017, pg. 10 ss.

MARISCAL DE GANTE, M. y LÓPEZ PASARO, E. “Transexualidad y Discriminación”, Revista Española de Derecho del Trabajo, nº 97, 1999, pg. 60 ss.

MEENAN, H. (ed.), Equality Law for an Enlarged Union: Understanding the Article 13 Directives, Cambridge: Cambridge University Press, 2007.

MOLINA NAVARRETE, C. "Diversidad de Orientación Sexual y Principio de Igualdad de Trato Laboral: ¿El Fin de la Diferencia entre Parejas de "Hecho" y de "Derecho"? (Comentario a la Sentencia del Tribunal de Justicia de la Unión Europea, de 12 de diciembre de 2013, asunto $n^{\circ}$ C-267/12)”, Estudios Financieros. Revista de Trabajo y Seguridad Social, $\mathrm{n}^{0}$ 371, 2014, pg. 171 ss.

MORALES ORTEGA, J.M. "Nuevos Fenómenos Discriminatorios: Homosexualidad y Transexualidad”, Relaciones Laborales, n 18, 1999, pg. 55 ss.

MULDER, J. "Dignity or discrimination: what paves the road towards equal recognition of same-sex couples in the European Union?” Journal of Social Welfare and Family Law, vol. 40, n 1, 2018, pg. 129 ss.

PAPADOPOULOU, G. "Sexual orientation and gender identity law in the European Union and its Court of Justice", en ZIEGLER, A.R. (ed.) Oxford Handbook of International LBGTI Law-Sexual Orientation, Gender Identity, Gender Expression and Sex Characteristics (SOGIESC) Law from an International-Comparative Perspective, Oxford: Oxford University Press, 2019.

PETERSEN, N. "The Principle of Non-discrimination in the European Convention on Human Rights and in EU Fundamental Rights Law”, en NAKANISHI Y. (eds.) Contemporary Issues in Human Rights Law. Singapore: Springer, 2018, pg. 129-142. https://doi.org/10.1007/978-981-10-6129-5_7

RAJAGOPAL, B. International Law from Below: Development, Social Movements and Third World Resistance, Cambridge: Cambridge University Press, 2003.

RIVAS VAÑÓ, A. LGBTI en Europa: la construcción jurídica de la diversidad, Valencia: Tirant lo Blanch, 2019.

RIVAS VAÑÓ, A. "La Prohibición de Discriminación por Orientación Sexual en la Directiva 2000/78”, Temas Laborales, n 59, 2001, pg. 193 ss. 
RIVAS VAÑÓ, A. y RODRÍGUEZ-PIÑERO ROYO, M. “Orientación Sexual y Derecho Europeo”, en FERNÁNDEZ LIESA, C. y MARIÑO MENÉNDEZ, F. La Protección de las Personas y Grupos Vulnerables en el Derecho Europeo, Madrid: Ministerio de Asuntos Sociales, 2001, pg. 293 ss.

SANCHEZ-URAN AZAÑA, Y. "El Principio de No Discriminación Sexual en el Derecho Social Comunitario: ¿Avance Sustancial del Tratado de Ámsterdam?”, en V.V.A.A., Estudios de Derecho del Trabajo y de la Seguridad Social en Homenaje al Profesor Juan Antonio Sagardoy Bengoechea, Madrid: Servicio de Publicaciones de la Facultad de Derecho de la Universidad Complutense, 1999, pg. 363 ss.

SELVANERA, G. "Gays in Private: the Problems with the Privacy Analysis in Furthering Human Rights” Adelaide Law Review, vol. 16, 1994, pg. 331 ss. SKIDMORE, P. "Sex, Gender and Comparators in Employment and Discrimination”, Industrial Law Journal, vol. 26, 1997, pg. 51 ss.

SMITH, R.A. y HAIDER-MARKEL, D.P. Gay and Lesbian Americans and Political Participation: a Reference Handbook, Santa Barbara: ABC-CLIO, 2002.

SPACKMAN, P. "Grant vs. South-West Trains: Equality for Same-sex Partners in the European Community”, American University Journal of International Law, $\mathrm{n}^{\circ}$ 12, 1997, pg.1063 ss.

STEHLÍK, V. "The CJEU crossing the Rubicon on the same-sex marriages? Commentary on Coman case”, International and Comparative Law Review, vol. 18, n 2, 2018, pg. 85 ss. DOI: 10.2478/iclr-2018-0039

STOPPIONI, E. "Une analyse critique de l'arrêt Coman: déconstruction de la consécration de l'obligation de reconnaissance du droit de séjour du conjoint homosexuel", European Papers, European Forum, 27 de febrero de 2019, pg. 1 ss. DOI: 10.15166/2499-8249/280

SURREL, H. (Dir.) Le Droit à la Non-Discrimination au Sens de la Convention Européenne des Droits de l'Homme, Actes du colloque des 9 et 10 novembre 2007 organisé par l'Institut de Droit Européen des Droits de l'Homme, Faculté de Droit, Université Montpellier, Bruselas: Bruylant Nemesis, 2008.

VICENTE PALACIO, M.A. “Transexualidad y Contrato de Trabajo”, Tribuna Social, $\mathrm{n}^{\circ}$ 67, 1996, pg. 55 ss.

VV.AA. "The Prohibition of Discrimination under European Human Rights Law” 2011, pg.14-21, accesible en http://ec.europa.eu/justice/discrimination/files/the_prohibition_of_discrimination_under _european_human_rights_law_update_2011_en.pdf

WAALDIJK, K. Extending rights, responsibilities and status to same-sex families: trends across Europe, Consejo de Europa y Ministerio de Asuntos Exteriores de Dinamarca, marzo 2018.

WAALDIJK, K. "The gender-neutrality of the international right to marry: Same-sex couples may still be excluded from marriage, but their exclusion - and their foreign marriages - must be recognized”, en ZIEGLER, A.R. International LGBTI, forth coming. 
WINTEMUTE, R. "Recognizing New Kinds of Direct Sex Discrimination: Transsexualism, Sexual Orientation and Dress Code”, Modern Law Review, vol. 60, 1997, en pg. 335 ss.

WINTEMUTE, R. "In Extending Human Rights, which European Court is Substantively 'Braver' and Procedurally 'Fitter'? The Example of Sexual Orientation and Gender Identity Discrimination" in MORANO-FOADI, S. y VICKERS, L. (eds.), Fundamental Rights in the EU: A Matter for Two Courts, Oxford: Hart Publishing, 2015. 